\title{
The Impact of the Coronavirus Pandemic on a Major Event Legacy: The 2020 National Collegiate Athletic Association Men's Basketball Final Four
}

\author{
Beth A. Cianfrone and Timothy Kellison \\ Georgia State University
}

\begin{abstract}
Following the cancellation of the 2020 National Collegiate Athletic Association Men's Basketball Final Four, the Atlanta Basketball Host Committee faced the unique challenge of executing a "postevent" wind-down amid a global health emergency and citywide stay-at-home mandate. While a significant portion of the host committee's tasks were completed in the days and weeks after the cancellation, one key component that lingered was event legacy. In this study, the authors examined how a local organizing committee's legacy planning was disrupted as a result of the coronavirus pandemic. Based on interviews with National Collegiate Athletic Association and host committee officials, direct and participant-based observation, and an analysis of local and social media reporting, the authors described the Atlanta Basketball Host Committee's pre- and postpandemic legacy plans. This study underscores the potential enduring nature of legacy plans, even during unprecedented crises that threaten the headlining event.
\end{abstract}

Keywords: community, event management, legacy planning, local organizing committee, mega-events, NCAA

During the 5-day window of April 3-7, 2020, thousands of basketball fans were set to descend upon Atlanta and be entertained by the National Collegiate Athletic Association (NCAA) Men's Basketball Final Four. In conjunction with the Final Four, the Division II and Division III Men's Basketball Championships, as well as the National Association of Basketball Coaches Convention, were also to be held in Atlanta that weekend. The NCAA staff and the Atlanta Basketball Host Committee (ABHC) planned the large-scale events, as well as numerous smaller community-related events. They secured more than 2,000 volunteers to host the events in multiple private and public facilities, including Mercedes-Benz Stadium, State Farm Arena, the Georgia World Congress Center, and Centennial Olympic Park. 
Due to the coronavirus pandemic (COVID-19), NCAA President Mark Emmert announced on March 11 that the Final Four events would be spectator free and then officially cancelled the events a day later, 3 weeks before they were to occur (Norlander, 2020). On March 24, Atlanta Mayor Keisha Lance Bottoms issued a stay-at-home order. Instead of being in the final weeks of preparation for hosting a major championship, the NCAA and ABHC quickly refocused their efforts to manage the logistics of a cancelled event. A major event, such as the NCAA Final Four, often provides a lasting legacy for the host community (e.g., Oja, Wear, \& Clopton, 2018). For the ABHC specifically, the event's impact and legacy for the community were now in question. Through this case study, we assessed the legacy-creation efforts of the NCAA and ABHC, despite the lack of an event, and investigated the impact the nonevent had on the host committee and community.

\section{Background}

With large-scale sport events, there is a residual impact on the community, whether in the form of economic gains, tourism, sociocultural benefits, or psychic impact (Karadakis \& Kaplanidou, 2012). The Final Four is the largest event managed by the NCAA. For the NCAA, the ABHC had numerous community outreach initiatives to implement, some with room for flexibility and creativity regarding how the host committee could execute the initiative, and others with more rigid NCAA guidelines regarding the execution.

The ABHC was "responsible for assisting with the planning and production of the 2020 NCAA Final Four and accompanying fan events ... its mission [was] to host a one-of-a-kind championship experience for student-athletes, participating institutions, fans and media" (Atlanta Basketball Host Committee, 2020a, para. 1). The ABHC was composed of nine board and 13 staff members, supported by one NCAA host institution, Georgia Tech. Carl Adkins, Executive Director of the $\mathrm{ABHC}$, and his staff began preparations for the Final Four more than a year before the event, with many staff transitioning from duties with the Atlanta Super Bowl Host Committee. The NCAA has five key objectives for the Final Four that the ABHC worked to support through various initiatives in Atlanta: (a) promote education as a brand, (b) align with key stakeholders, (c) enhance the tournament experience, (d) expand the demographic, and (e) create a premium tournament experience (C. Mouton, personal communication, April 15, 2020). A major role of the $\mathrm{ABHC}$ was to provide a "lasting and positive impact on the community, working with the NCAA, corporate partners, and contractors to execute their objectives" (C. Mouton, personal communication, April 15, 2020).

A series of host committee programs included Read to the Final Four (an elementary-school-based, citywide, bracket-style reading series), the Legacy Restoration Project presented by AXE (renovation of local youth recreation center), the NCAA Final Four Dribble presented by Buick (a free youth event), Fan Jam grassroot marketing activations (interactive mobile "pop-up" events with a branded truck and basketball court), sustainability initiatives, and an educational initiative with local universities, all of which are reoccurring annual projects at the Final Four. ABHC Community Director Chincie Mouton noted, "We want the 
people of Atlanta to feel good about having the Final Four; it's truly for the city of Atlanta ... we want it to be inclusive for the city as a whole" (personal communication, April 15, 2020). In other words, these events would allow Atlantans who were unable to access Final Four tickets to still partake in the excitement of NCAA Men's Basketball.

\section{Method}

As part of the educational outreach initiative, ABHC Executive Director Carl Adkins had a vision of including as many universities and sport management students as possible in the planning and execution of the ancillary events. This program was overseen by Matt Snyder, Vice President of Volunteer Programs and Academic Liaison. In total, 214 sport management students across nine universities in the greater Atlanta region were set to be Street Team volunteers. Georgia State University served as the Host Committee's sport management educational partner. Thus, we were a part of the planning process since June 2019. Through this partnership, the Georgia State University faculty hosted a speakers' event with the NCAA and ABHC in January, had two students intern with the ABHC, and taught a special topics Event Management course, which centered on the Final Four and featured NCAA and ABHC speakers each week. As part of the course, the 25 students were to serve as the lead volunteers, known as Point Guards, of the Final Four Street Team for the 4 days of the events. The Street Team is responsible for providing customer service to visitors/spectators. The class was also responsible for planning an on-campus marketing activation with the Fan Jam and developing a volunteer handbook.

As a result, we attended monthly NCAA Wrap Up, Volunteer, and Sustainability Committee meetings. Following the cancellation of the Final Four, we conducted informal interviews with five key stakeholders from the NCAA and ABHC. The empirical material collected from these individuals represents the knowledge and awareness of several high-ranking officials who were directly involved in the planning of the Final Four in Atlanta. Therefore, this study benefits from its access to high-level managers, whose positions in the NCAA and ABHC contribute valuable insight into the ways in which legacy planning was altered following the event's cancellation. The accuracy and significance of the empirical material collected are strengthened by the expertise of these respondents. These discussions, as well as direct and participant-based observations and reviews of related news and social outlets, serve as the lens through which we analyzed the ABHC's efforts to deliver a positive, lasting legacy to Atlanta despite the cancellation of the Final Four and the city's enforcement of a stay-at-home order.

\section{Postcancellation Community Impact}

The ABHC was notified minutes after the NCAA announced the cancellation of the event. Amid all of the uncertainty on that day, everyone we spoke with at the $\mathrm{ABHC}$ had the same sentiment about the cancellation of the event-they were disappointed they could not see it to fruition, but knew the safety of the studentathletes, patrons, and others involved was most important, and graciously thanked 
us for our efforts and involvement. It was clear that the ABHC staff was flexible and could pivot in moving forward to manage in postevent mode. Unlike other U.S. sporting events that were postponed or cancelled during this time, the Final Four was arguably the largest host-based event that was being impacted. Furthermore, the NCAA has already designated the Final Four sites for the next 6 years; the ABHC staff would not have a chance to host again in the foreseeable future. It became a unique situation for the $\mathrm{ABHC}$, who shifted to manage the event cancellation and fulfillment of community efforts, while most of its staff was only on contract through May 15, 2020.

The ABHC staff needed to determine the extent to which they could continue community outreach in light of the city of Atlanta's stay-in-place mandate and restriction on large gatherings. The mindset, according to Mouton, was "We can't execute the way that we wanted, but we still have a way to close out and finish" (personal communication, April 15, 2020).

The Read to the Final Four program continued, initially built as an online competition, and its reading platform usage was extended to June. In that light, the online program became an unexpected tool in the school system's transition to e-learning. Yet, the celebration for the Final Four reading teams from the competition remains postponed until it is safe to resume group gatherings at schools. A youth clinic and the Legacy Restoration Project, which centered on revitalizing a local Boys \& Girls Club and holding a ribbon-cutting ceremony with sponsor AXE, were planned for Final Four week. Those are to be rescheduled when safely allowable. Due to the ABHC staff's short-term contracts, however, there may not be host committee members at that point, potentially leaving it to the NCAA or ABHC staff on their own to complete these elements. As Mouton acknowledged, "while I probably won't be on the host committee at that time, we will follow through on the commitment to those students" (personal communication, April 15, 2020). The coordination of the final celebration will be completed by her or the NCAA staff.

For the university educational components, student-led Fan Jams and oncampus marketing activations planned for the week before the Final Four events were cancelled. However, five ABHC staff members still fulfilled their commitments to join video calls for the Event Management class.

Along with the decisions about which community legacy projects could still be continued came the decision to manage the vast number of products that were directly related to the community events. The majority of the Final Four event materials are event-specific and branded pieces, leaving them unusable for future events. The $\mathrm{ABHC}$ met and took inventory of the materials to determine which were unusable and which could be returned to the NCAA for future use. From this, they put together a donation list to allow them to still make a difference in the Atlanta community. The decision to donate items provided community impact and aided sustainability efforts with the reuse of the items. Notably, the Final Four Dribble event, in which thousands of children would be provided free Final Four basketballs to dribble through the streets of Atlanta together, was cancelled. Instead, the ABHC donated the basketballs to the Boys \& Girls Clubs of Metro Atlanta in early May. The branded Fan Jam basketball court was being donated to the renovated Boys \& Girls Club from the Legacy Restoration Project. 
Corporate partners also played a role in the recovery of items. The staff with Coca-Cola was set to serve as sustainability green team volunteers for the Final Four. Instead, the ABHC provided Coca-Cola with the clear bags (originally intended to distribute to Final Four visitors) to donate to organizations that need them. It was apparent that the ABHC staff was resourceful and pragmatic with their donations.

In the case of the 2020 Men's Final Four, the volunteer uniforms and packets were purchased by the NCAA and were clearly marked as Final Four 2020 Atlanta branded items. The volunteer packet included a white polo shirt, hat, poncho, flashlight, and clear drawstring backpack. Due to the timing of the cancellation announcement, volunteer meetings had not occurred yet, other than our Georgia State University class session, which was held minutes after the NCAA announced the game would be played without spectators. With the city of Atlanta's stay-inplace orders, in addition to the restriction on large gatherings, it would not have been feasible to distribute volunteer uniforms. Thus, after the event was cancelled completely, the ABHC searched for an outlet to distribute the uniforms that would benefit those serving in the community. The ABHC provided the packets to 19 Atlanta community recreation centers, where school and center staff handed out school lunches to students impacted by the school closures. These front-line volunteers issuing the food could use the ponchos and shirts as protective barriers, and gain a unique piece of memorabilia for their efforts.

During this same time, on April 1, individuals who registered to be Final Four volunteers $(2,100)$ were emailed an update about the event. The message included information about how the event could not continue, the ABHC's donation of the volunteer kits, the status of the volunteer Facebook page, and a survey about their experience. Snyder indicated that, of the survey respondents $(N=400)$, many intended volunteers noted they were proud of the way the host committee was redistributing the goods and helping the community (personal communication, April 8, 2020). In addition, many shared the same disappointment of not being able to participate as the host committee, but appreciated the efforts of the committee and hoped for future opportunities.

However, the good deeds were not met with unanimous community support. Some of the registered volunteers $(20 \%)$ were upset that they did not receive the uniforms and felt they deserved them (M. Snyder, personal communication, April 8, 2020). This sentiment was interesting, considering the registered volunteers did not have an opportunity to be a part of an ABHC Final Four training session or volunteer. Moreover, some individuals recognized the challenges with distributing to the large groups, given the city restrictions, as a reason for not receiving the uniforms and responded with advice on how to make packet pickup work logistically, by staggering when people picked up the uniforms. It was evident that the branded Atlanta Final Four volunteer uniform provided individuals the opportunity to feel connected with the event and a sense of belonging to and pride in the community, even in the face of a pandemic. The lead ABHC volunteer staff members worked in the same capacity with the Super Bowl the previous year, and many of the volunteers were from the same list. They agreed that their volunteers were passionate, took ownership of their participation in the event, and appreciated nice uniforms and gifts. As with all major events, volunteers are a vital component and front-facing service personnel. 
The ABHC communication staff played a key role in providing information to volunteers, spectators, and key stakeholders. The Final Four social media accounts (Facebook@TheFinalFour/Twitter@FinalFour), as well as a private Final Four Volunteer Facebook page, were managed by the ABHC staff and are also a representation of Atlanta. As noted from reviewing the social accounts, NCAArelated decisions sometimes created a negative public impact for the $\mathrm{ABHC}$ and community. Notably, when the NCAA announced the ticket reimbursement process, which allowed full refunds for the ticket, but not for the processing fees, spectators provided criticism of the ABHC's social accounts, making it seem as though it was a host committee decision.

The ABHC staff was proud of its follow-through with the legacy plan. The ABHC media team developed a press release and social media posts (see Figure 1) in an effort to showcase the community impact from the event. This sentiment received traction across Atlanta on local television news broadcasts and in newspapers. As Adkins noted,

Serving as the host city for the Final Four extends far beyond the games, and it is important we recognize the positive impact on students throughout Georgia from elementary schools to our leading universities. The activations and attention to detail that went into planning and preparing for the Final Four and DII, DIII Championship is something the entire Atlanta community should be proud of and we are grateful to have such incredible partners who were there every step of the way. (Atlanta Basketball Host Committee, 2020b, para. 6)

Adkins's comments underscore the significant undertaking associated with planning legacy-related ancillary events. In addition, implicit in his statement is an acknowledgment that his staff's community-related efforts in the metro-Atlanta area would be left largely unrecognized.

An interesting takeaway from this case is that, although the cancellation of the 2020 Men's Final Four effectively ended the men's basketball tournament, it did not lead the ABHC to immediately cease its operations. Clearly, there was a need for communications, ticketing, and staffing personnel to draw all tournamentrelated activities to a close, but much of this work occurred in the days and weeks following the cancellation. On the other hand, the ABHC's legacy team has maintained its commitment to holding its events in the future. These tentative plans will continue to be complicated by the persistence of the pandemic and the likelihood that government regulations will limit-or profoundly shape-the occurrence of public gatherings in the foreseeable future.

\section{Future Direction}

We wait to see if and how major events return to society and how sport organizations move forward with major events, specifically the legacy and community impact related to the events. If spectators are limited, ancillary, fan-related events around large-scale sporting events may also be limited, along with the community impact. Much of the host committee process is focused on the tourism aspectout-of-area visitors and economic impact would be lessened. Does the role of 


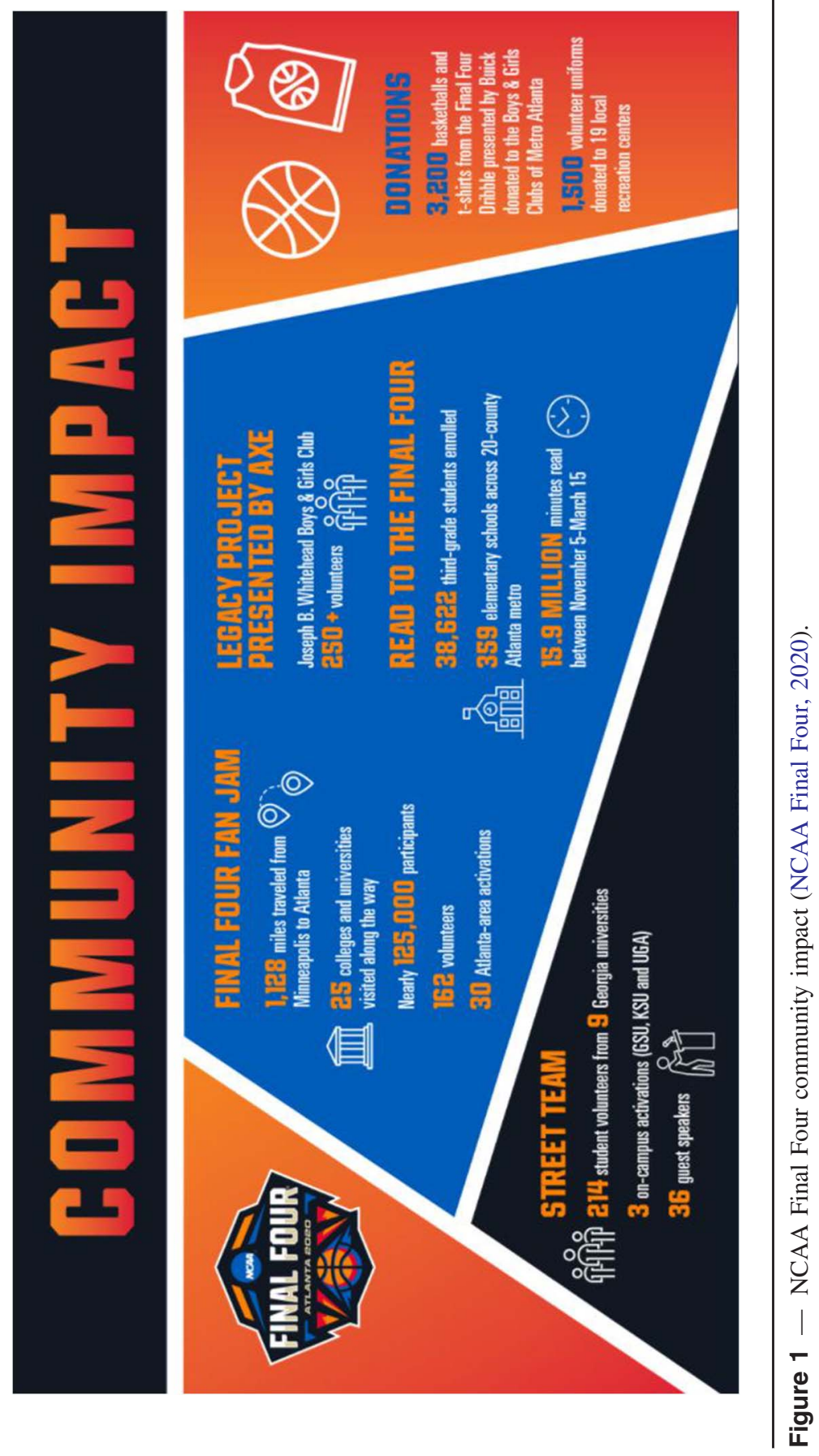


legacy and impact of sport on a community decrease without fans, or does it need to be greater to make the community feel a part of the hosting process and provide justification for the city spending money on the event? A main reason sport organizations and, subsequently, host committees invest in and support community efforts is to provide positive justification for hosting the events in the city. The events bring positive recognition, economic impact, and other benefits to the community. Yet, community support is often needed to help fund aspects of the bid process or stadiums, which make the city attractive to host major events. Sport organizations and host committees have a need to mitigate the concerns of citizens who are negatively impacted by major events, whether through paying for increases in taxes for new stadiums or other sport-related enhancements or enduring traffic or crime that may occur during a major event.

As discussed previously, a key implication of this case is that a major sporting event's legacy can endure despite the cancellation of the event itself. Given the substantial investment of time and money by a host community and local organizing committee, and in light of the growing number of events being cancelled or postponed indefinitely because of the coronavirus pandemic, sport managers may look to their legacy plans as a vehicle for promoting the event's positive impact on the community, even if the event itself cannot happen due to public health concerns.

\section{References}

Atlanta Basketball Host Committee. (2020a). About. Retrieved from https://finalfouratl. com

Atlanta Basketball Host Committee. (2020b, April 6). Atlanta Basketball Host Committee donates unused final four sports equipment and volunteer kits to Boys \& Girls Clubs of Metro Atlanta and City of Atlanta Department of Parks and Recreation [Press release]. Retrieved from https://finalfouratl.com/atlanta-basketball-host-committee-donatesunused-final-four-sports-equipment-and-volunteer-kits-to-boys-girls-clubs-of-metroatlanta-and-city-of-atlanta-department-of-parks-and-recreation/

Karadakis, K., \& Kaplanidou, K. (2012). Legacy perceptions among host and non-host Olympic Games residents: A longitudinal study of the 2010 Vancouver Olympic Games. European Sport Management Quarterly, 12(3), 243-264. doi:10.1080/ 16184742.2012.680067

NCAA Final Four [FinalFour]. (2020, April 9). NCAA final four community impact [Tweet]. Retrieved from https://twitter.com/FinalFour?ref_src=twsrc\%5Egoogle $\% 7$ Ctwcamp\%5Eserp\%7Ctwgr\%5Eauthor

Norlander, M. (2020, March 16). The end of march madness: Behind the scenes in the hours that led to the cancellation of the NCAA tournament. CBS Sports. Retrieved from https://www.cbssports.com/college-basketball/news/the-end-of-march-madness-behindthe-scenes-in-the-hours-that-led-to-the-cancellation-of-the-ncaa-tournament/

Oja, B.D., Wear, H.T., \& Clopton, A.W. (2018). Major sport events and psychic income: The social anchor effect. Journal of Sport Management, 32(3), 257-271. doi:10.1123/ jsm.2016-0170 